much higher than that of similar depths in the oceans. The numerous large quantities of mud obtained by the grab were almost, but not quite, devoid of life.

The coral cappings on those of the submarine hills which reach the surface or nearly so would seem to be similarly situated ecologically to the atolls of the Indian and Pacific oceans, and, as coral growth round their rims is in full vigour, it was expected, in accordance with the theories of growth of atolls, that their slopes would be covered by fallen coral debris. This was found to be the case only to a quite inconsiderable extent; indeed throughout our exploration, recognisable coral debris is confined to quite shallow water. It was also surprising to find that several shoals examined by the grab are not, as would be expected in a sea so full of coral growth, growing towards the surface, but, though small living corals are present, are evidently in process of decay, as shown by the dead and decayed masses of coral brought up: boring organisms are much more abundant in these masses than in the surface reefs. The decay appears to be rapid, since our soundings are deeper than those recorded only sixty years ago. This state of things corresponds with surface reefs in this neighbourhood, some of which are in full vigour, others stationary or in decay ; some shoals visible from above are covered completely with growing corals, on others are few or none. Our knowledge of coral ecology is still very imperfect. Between the reefs down to $50 \mathrm{fm}$. at least, the bottom is in many places rough and rocky, the nature of the rock being at present unknown. Dead and partly living corals only were secured.

The southern part of the Gulf of Aqaba was also explored. The difference between this and the Gulf of Suez is well known; against the average depths of 30-40 fm. of the flat-bottomed Gulf of Suez we have in Aqaba soundings up to $700 \mathrm{fm}$., but by making courses transverse to the Gulf we discovered a deep trough $900-1,000 \mathrm{fm}$. deep, well over to the eastern side. This narrow gulf, only about 14 miles wide, thus has a depth nearly as great as that of the Red Sea, which itself is deeper in proportion to breadth than any other. From this depth of water the mountains rise sheer, making one of the most wild and desolate coasts in the world, beside which the deserts and mountains of the Gulf of Suez are a mild and smiling landscape. The maritime plain, so characteristic of the Red Sea shores, where it is generally up to 20 miles wide, is here almost absent, but represented even on some of the most abrupt mountain shores by patches of sedimentary rocks clinging to their bases just above water-level. The immense quantities of alluvial gravels which must have resulted from the denudation of the hills in the past disappeared before the Miocene sedimentary rocks were laid down, showing that the rifting of the valley was in two stages, separated by considerable geological time.

${ }^{1}$ Crossland, C., J. Linn. Soc., 31, 26 and 284.

\title{
Methods of Estimating Underground Oil Reserves
}

$\mathrm{M}^{\mathrm{R}}$ R. V. BILIBIN'S report on his method of estimating underground oil reserves has been accepted by the Organisation Committee of the International Geological Congress, and will be considered at the seventeenth session of that Congress to be held in Moscow in 1937. In the meantime, it is being circulated by the Committee with the view of obtaining criticisms and further contributions to this somewhat complicated problem of accurate assess. ment of oil reserves.

According to Mr. Bilibin's method, the first step is to divide up a general geographical map of the country to be surveyed into various groups of areas by means of colours, the division being based on corresponding available data and geological reasoning. It is suggested that the total surface area be divided into groups of areas as follows: those which have already been exploited for oil; those which, tested by deep drilling, are known to be economically oil-bearing; those considered potentially economically oil-bearing as a result of geophysical and prospecting work; those for general geological reasons considered favourable but which have not been tested, or have been insufficiently tested; those for which no estimate of reserves is available; and those considered as non-oil-bearing.

The total surface area of each of the first four groups is used as a basis of calculation. Distinction is then made between the different types of reserves available in each group. Five categories of reserves are suggested, namely, prepared reserves obtainable from producing wells; explored reserves obtainable from new wells in a prospected horizon and within its fixed boundaries; possible reserves obtainable either from parts of prospected horizons, the boundaries of which have not been fixed, or from discovered, but insufficiently tested horizons; supposed reserves obtainable from the first two groups of areas from horizons proved to be oil-bearing by geological data, or estimated to be so by geological considerations; and possible reserves obtainable from areas where prospecting has been favourable. Reserves falling within the different categories are then estimated either by a method of relation curves based on initial production, well-spacing and number of wells per horizon, or by a saturation method which is a mathe. matical calculation of the ultimate product obtainable from a given horizon, dependent on the volume of the bed, porosity, saturation and recovery factors.

It will be noted that in this method of estimating underground reserves of economic importance, only those are included which are obtainable by wells from each horizon by modern methods of exploitation. Those obtained by so-called secondary methods are not included as it is not at present possible to find out definitely to which horizons these methods can be effectively applied; nor are there sufficient data to show how exploitation can be increased by using these methods. 